\title{
Nível sérico da vitamina A em crianças portadoras de leishmaniose visceral
}

\author{
Vitamin A serum level in children with visceral leishmaniasis
}

\author{
Kleber Giovanni Luz', Regina Célia de M. Succi² e Elizabeth Torres ${ }^{3}$
}

\begin{abstract}
Resumo A vitamina A tem sido considerada uma vitamina anti-infecciosa e sua deficiência está associada a um maior risco de infecções graves, como ocorre por exemplo no sarampo. Nos países em desenvolvimento a hipovitaminose A é um grave problema de saúde pública. O objetivo deste estudo é quantificar o nível sérico da vitamina $A$ em pacientes pediátricos portadores da leismaniose visceral (LV). Amostras de sangue foram coletadas de 22 crianças portadoras de $L V$, estocadas em freezer e posteriormente, quantificado o nível de vitamina A usando-se a cromatrografia líquída de alta eficiência, nove irmãos assintomáticos dos pacientes foram usados como controles. A média do nível sérico da vitamina A nos portadores de $L V$ foi de $21,38 \mu \mathrm{g} /$ $100 \mathrm{ml}$ e no grupo controle foi de $31,39 \mu \mathrm{g} / 100 \mathrm{ml}$. Entre os pacientes estudados com LV a média do nível sérico de vitamina $A$ encontrado foi significativamente menor, utilizando-se o teste $t$ de Student para um $p<0,01$ que dos controles.
\end{abstract}

Palavras-chaves: Leishmaniose visceral. Vitamina A. Hipovitaminose A. Calazar.

Abstract Vitamin $A$ is considered an anti-infectious disease vitamin, and its deficiency is associated with severe infections such as in measles. In developing countries the low concentrations of vitamin $A$ are a public health problem. The aim of this study is to describe serum vitamin A concentrations among children with visceral leishmaniasis (VL). Blood sample was collected from 22 children with VL, and stored in a freezer, 9 siblings, with no clinical signs of the VL patients had their blood collected for a control group. Samples were assayed by high performance liquid chromatography. The median vitamin A concentration in the LV group was $21.38 \mu \mathrm{g} / 100 \mathrm{ml}$ and in the control group it was $31.39 \mu \mathrm{g} / 100$. The mean in the $\mathrm{LV}$ was statistically lower than in the control group, using Student's test, $p<0.01$.

Key-words: Visceral leishmaniasis. Vitamin A. Hypovitaminosis A. Calazar.

O calazar ou leishmaniose visceral (LV) é uma doença tropical que se caracteriza pela presença de febre, hepatoesplenomegalia,pancitopeniae hipergamaglobulinemia ${ }^{12}$. Sua ocorrência predominava em áreas rurais, entretanto, nos últimos anos tem ocorrido surtos em áreas periurbanas como é o caso das cidades de São Luis, no Maranhão, Teresina, no Piauí e Natal, no Rio Grande do Norte. Em geral, a letalidade do calazar situa-se em 10 a $15 \%$ e os dados epidemiológicos demonstram um aumento nos coeficientes de mortalidade que passaram de 0,04/100.000 em 1980 para $0,09 / 100.000$ em 1990 ao contrário do que ocorre em países desenvolvidos onde a letalidade é próxima a $z^{2}{ }^{4}$. Estes dados tornam esta endemia uma prioridade de saúde pública no Brasil11.

Sabe-se que a desnutrição é um fator de risco para o desenvolvimento da doença clínica nas crianças, mas pouco se tem publicado sobre o papel dos micronutrientes no calazar ${ }^{1}$.
A vitamina $A$ é essencial na imunidade e a sua deficiência está relacionada a um aumento da morbidade e mortalidade por doenças infecciosas ${ }^{10}$ 9 , esta vitamina é fundamental para o crescimento e função da célula T e sua suplementação está associada a uma queda na morbidade e mortalidade em doenças infecciosas na infância, como é o caso do sarampo, e é uma das medidas de saúde pública mais efetiva, quando consideramos a relação custo/ benefício6 79 . O Interdependent Committee on Nutrition for National Defense estabeleceu um ponto de corte para a interpretação do nível sérico da vitamina $A$, sendo considerado deficiente nível sérico < $10 \mu \mathrm{g} / \mathrm{dl}$; baixo entre 10,0 e $19,9 \mu \mathrm{g} / \mathrm{dl}$; aceitável entre 20 e $50 \mu \mathrm{g} / \mathrm{dl}$ e normal acima de $50 \mu \mathrm{g} / \mathrm{dl}^{2}$.

O objetivo deste trabalho foi comparar os níveis séricos da vitamina A de crianças com leishmaniose visceral, com os de um grupo controle, em uma região endêmica para o calazar.

\footnotetext{
1. Universidade Federal do Rio Grande do Norte, Natal, RN. 2. Universidade Federal de São Paulo, SP. 3.Faculdade de Saúde Pública da Universidade de São Paulo, São Paulo, SP.

Endereço para correspondência:Dr. Kleber Giovanni Luz. R. Desembargador Túlio Bezerra de Melo 3631/1000, Candelária, 59064-580 Natal,RN, Brasil. Fax: 5584 206-3221.

e-mail:luz@digi.com.br

Recebido em 18/7/2000
} 


\section{MATERIAL E MÉTODOS}

Foram incluídos na investigação pacientes portadores de calazar, admitidos no Hospital Infantil Varela Santiago e Hospital Giselda Trigueiro, localizados na cidade de Natal, capital do Estado do Rio Grande do Norte. Os pacientes para terem sido considerados casos deveriam preencher os seguintes critérios de inclusão:

ter o diagnóstico de leishmaniose visceral confirmado pelo mielograma, com o encontro de formas amastigotas da Leishmania;

ter idade mínima de 6 meses e máxima de 18 anos, até o dia do diagnóstico;

os pais ou responsáveis terem assinado o termo de consentimento;

todos os pacientes deveriam ser virgens de tratamento com antimoniais pentavalentes.

Critérios de exclusão:

não deveriam ter recebido dose suplementar de vitamina A por via oral ou parenteral nos últimos 3 meses; do calazar:

não deveriam apresentar outra doença além

Foram incluídos como grupo controle os indivíduos que preenchiam os seguintes critérios:

. $\quad$ ser irmão de um paciente hospitalizado com o diagnóstico de calazar; casos:

morar no mesmo domicílio dos pacientes

não apresentar sintomas (febre, perda de peso, ou hepatoesplenomegalia) relacionados ao calazar; não apresentar no momento da coleta da amostra de sangue qualquer sinal clínico de outra doença em atividade.

. deveriam ter idade mínima de 6 meses e máxima de 18 anos;

os pais ou responsáveis terem assinado o termo de consentimento.

Todos os pacientes que apresentaram nível sérico baixo ou deficiente de vitamina $A$ foram convidados através do serviço social dos dois hospitais a retornarem ao ambulatório de seguimento dos pacientes egressos a fim de receberem uma dose suplementar da vitamina $A$ de 50.000 unidades por via oral. As comissões de ética de ambos os hospitais aprovaram o protocolo de investigação.

Um total de 22 pacientes portadores de calazar e nove controles foram submetidos a história clínica, exame físico e dosagem sérica da vitamina $A$. As coletas foram realizadas entre julho de 1997 e janeiro de 1999. Tubos de vidros com anticoagulante (EDTA) e agulhas descartáveis foram usados para extrair a quantidade de sangue requerida, através da veia cubital. Cerca de $3 \mathrm{ml}$ foram coletados; as coletas ocorreram em condições de jejum; as dosagens da vitamina A foram realizadas na Faculdade de Saúde Pública da Universidade Estadual de São Paulo, através da High pressure liquid chromatography e expressa em microgramas $/ \mathrm{ml}$. Utilizou-se, para tal dosagem, um espectrofotômetro tipo Colemam, modelo 295.

Os dados do grupos 1 (casos) e grupo 2 (controles) foram analisados e comparados, através de testes não paramétricos, utilizando-se o teste do $\mathrm{x}^{2}$ qui-quadrado ou teste $\mathrm{t}$ de Student.

\section{RESULTADOS}

O nível sérico da vitamina $A$ foi determinado em 31 crianças sendo 22 casos e 9 controles. Os pacientes com LV apresentavam quadro

clínico clássico e todostinham febre e hepatoesplenomegalia enquanto os controles eram assintomáticos (Tabela 1).

Tabela 1- Características clínicas dos casos e controles.

\begin{tabular}{|c|c|c|c|c|c|c|}
\hline & \multicolumn{3}{|c|}{ Febre prolongada } & \multicolumn{3}{|c|}{ Hepatoesplenomegalia } \\
\hline & & $\mathrm{n}^{\circ}$ & $\%$ & & $\mathrm{n}^{\circ}$ & $\%$ \\
\hline Casos & presente em & 22 & 100,0 & presente em & 22 & 100,0 \\
\hline Controles & ausente em & 9 & 100,0 & ausente em & 9 & 100,0 \\
\hline
\end{tabular}

A freqüência de meninos e meninas foi igual em ambos os grupos para um $\mathrm{p}<0,01$, através do teste qui-quadrado, como visto na Tabela 2.

\begin{tabular}{lcc} 
Tabela 2 & - Freqüência quanto ao sexo nos casos de LV e controles. \\
\hline Sexo & Casos & Controles \\
\hline Masculino & 12 & 7 \\
Feminino & 10 & 2
\end{tabular}

A média de idade entre os casos e controles não apresentou diferença para um $\mathrm{p}<0,01$, através do teste t de Student. (Tabela 3 ). 
A média do nível sérico da vitamina A nos casos de LV e controles é apresentada na Tabela 4.

A média dos níveis séricos em $\mu \mathrm{g} / 100 \mathrm{ml}$ nos controles foi significativamente maior do que 0 encontrado nos pacientes, para um $\mathrm{p}<0,01$, utilizando-se o teste $\mathrm{t}$ de Student. Entre os pacientes portadores do calazar, 14 tiverem a quantificação do nível sérico da vitamina A normal, $2(<10 \mu \mathrm{g} / \mathrm{l})$ deficiente e 6 baixo $(10 \mu \mathrm{g} / \mathrm{l}<\mathrm{e}<20 \mu \mathrm{g} / \mathrm{l})$, fato que não ocorreu entre os controles.

Tabela 3 - Média de idade entre os casos de LV e controles

\begin{tabular}{lc} 
& Média de Idade (anos) \\
\hline Pacientes com $\mathrm{LV}^{*}$ & 3,9 \\
Controles & 6,1 \\
\hline
\end{tabular}

Tabela 4 - Média do nível sérico da vitamina $A$ nos casos de $L V$ e controles.

\begin{tabular}{lc}
\hline \multicolumn{1}{c}{ Média de nivel sérico } \\
\hline 1. Pacientes com LV & $21,38 \mu \mathrm{g} / 100 \mathrm{ml}$. (9,51 a $37,09 \mu \mathrm{g} / 100 \mathrm{ml})$ \\
2. Controles & $31,39 \mu \mathrm{g} / 100 \mathrm{ml}$. (23,8 a $4 \mu \mathrm{g} / 100 \mathrm{ml})$ \\
\hline
\end{tabular}

\section{DISCUSSÃO}

Pouco se tem estudado sobre o papel dos micronutrientes no calazar, apesar da deficiência de micronutrientes ser comum em regiões de ocorrência do calazar ,como é o caso do semi-árido nordestino ${ }^{8}$. Em 1983 Muigai $^{5}$, estudando 10 pacientes ,demonstrou que a absorção da vitamina $A$ e da d-xylose estava prejudicada em 7 destes pacientes portadores da leishmaniose visceral. Referiu ainda que em 5 dos 10 pacientes a presença de amastigotas da leishmania, presente na mucosa intestinal, estava associado a um infiltrado linfocitário e plasmocitário, e em 2 encontrouse uma atrofia vilositária. Estes achados poderiam ser os fatores que explicariam a má absorção da d-xylose e da vitamina $A$, embora não encontrassem relação entre a intensidade do parasitismo e a má-absorção da vitamina $A$. Estas duas deficiências foram revertidas após a terapia com antimonial pentavalente.

Muito se tem publicado sobre o papel da vitamina A em patologias infecciosas. Ela é considerada uma vitamina anti-infecciosa desde 1920, mas recentes publicações têm comprovado este fato experimentalmente, como é o caso do nível sérico baixo de vitamina A ser um fator de risco para a transmissão materno-fetal do HIV; pacientes com malária falciparum têm, após uma suplementação da vitamina $A$, um prognóstico melhor, pois tem os episódios clínicos, a esplenomegalia e a densidade parasitária influenciados positivamente por esta suplementação ${ }^{10}$.

A hipovitaminose $A$ afeta cerca de 100 milhões de pessoas no mundo. Por ser o nordeste do Brasil área endêmica para hipovitaminose $A^{8}$ e ser nesta região 0 local de ocorrência de cerca de $90 \%$ dos casos de LV anualmente notificados do país ${ }^{11}$, acreditamos que um estudo descritivo do nível sérico da vitamina $A$ em pacientes pediátricos ajudaria na compreensão do papel que este micronutriente pode representar nos pacientes portadores da leishmaniose visceral.
Este estudo é o primeiro estudo descritivo dos níveis séricos da vitamina $A$ em pacientes pediátricos com calazar, utilizando-se a HLPC ( High performance liquid chromatography).

Classicamente, a avaliação em uma população da deficiência de vitamina $A$ pode ser feita de múltiplas maneiras, mas laboratorialmente existem duas, a primeira é dosar a reserva hepática (método histopatológico) deste micronutriente no tecido hepático, prática pouco utilizada pelas dificuldades técnicas óbvias. A segunda é quantificando o nível sangüíneo desta vitamina, utilizando para tal fim a HLPC, sendo este método capaz de detectar níveis abaixo de $10 \mu \mathrm{g} / 100 \mathrm{ml}$, que segundo o Interdependent Committee on Nutrition for National Defense(ICNND), seria um nível deficiente ou indetectável. A dosagem do nível sérico é, na prática, interpretado como uma avaliação próxima da reserva corporal desta vitamina ${ }^{2}$. Entre os 22 pacientes com calazar, 2 apresentavam nível sérico da vitamina $A$ abaixo de $10 \mu \mathrm{g} / 100 \mathrm{ml}$, equivalente ao encontrado em situações de extrema deficiência nutricional. A média do nível sérico da vitamina $A$ foi menor nos pacientes $(21,38 \mu \mathrm{g} / 100 \mathrm{ml})$ do que nos controles $(31,39 \mu \mathrm{g} / 100 \mathrm{ml})$, esta última média é comparável a média de crianças portadoras da SIDA nos Estados Unidos da América, que é de $31,00 \mathrm{~s} \mu \mathrm{g} / 100 \mathrm{ml}$ assim como de crianças americanas saudáveis, mas é maior do que a média encontrada em crianças americanas com sarampo ou infecção pelo vírus sincicial respiratório ${ }^{6}$.

Várias são as possibilidades fisiopatológicas para o encontro do baixo nível sérico de vitamina $A$ : ingesta deficiente; absorção intestinal prejudicada ou ainda uma excreção urinária exacerbada da vitamina A. Independente do mecanismo fisiopatológico o resultado será sempre o mesmo, ou seja, uma deficiência sérica do retinol .

A primeira possibilidade é a causa mais comum de hipovitaminose A no terceiro mundo e no nordeste do 
Brasil, região de onde os pacientes eram procedentes. Entretanto, a epidemiologia da leishmaniose visceral tem mudado nos últimos 10 anos, de doença de áreas rurais, para regiões periurbanas onde há melhores programas de assistência social. Desta forma, é possível que uma dieta pobre em retinol, a ponto de levar a uma deficiência do retinol, seja menos provável de ocorrer. Ademais, nos controles não houve níveis baixos de vitamina A. A segunda explicação é que os pacientes, apesar de terem uma dieta adequada no conteúdo de vitamina A teriam a sua absorção prejudicada pela má absorção induzida pela presença da leishmania na mucosa intestinal, como demonstrado em 1983, por Mugai $^{5}$, esta seria a principal possibilidade, mas somente realizando-se testes de absorção da vitamina A é que poderíamos chegar a esta conclusão .

Finalmente, uma excreção aumentada e duradoura deste micronutriente através da urina poderia ser a causa da diferença encontrada entre os dois grupos.
Os episódios febris e diarréicos freqüentes, no quadro clínico do calazar poderiam colaborar para este achado bioquímico de hipovitaminose pois citocinas inflamatórias, como a interleucina 1 e o fator de necrose tumoral levam a uma proteinúria febril, resultante de uma reabsorção tubular defeituosa, este dano possibilitaria a passagem renal da RBP (retinol binding protein), que é uma proteína de baixo peso molecular, através do glomérulo renal, aumentando a excreção urinária da vitamina $A^{3}$. Entretanto, não foi dosada a excreção urinária destes pacientes da vitamina $A$ o que comprometeria esta conclusão fisiopatológica.

Acreditamos que os pacientes com diagnóstico definido da doença poderiam ser submetidos a uma suplementação oral da vitamina A com o objetivo de se minimizar os efeitos de uma deficiência deste micronutriente, sejam eles relacionados a visão ou sejam eles relacionados a uma maior dificuldade de resolver a infecção pela leishmânia.

\section{REFERÊNCIAS BIBLIOGRÁFICAS}

1. Badaró R, Jones TC, Lourenço R, Sampaio D, Carvalho EM, Rocha H,Teixeira R,Johnson Jr WD. A prospective study of visceral leishmaniasis in an endemic area of Brazil. Journal of Infectious Diseases 154:639-649,1986.

2. Interdepartmental Committee on Nutrition Survey. Government Printing Office, Washington DC,1963.

3. Jordão Jr AA, Figueiredo JFC, Silveira S, Junqueira-Franco MVM, Vannuchi H.Excreção urinária de vitamina $A$ e substâncias reativas ao ácido tiobarbitútrico em pacientes com AIDS. Revista do Hospital das Clínicas da Faculdade de Medicina de São Paulo 53:11-15,1998.

4. Minodier P, Piarroux R, Garnier J, Unal D, Perrimond H, Dumon H. Pediatric visceral leishmanioses in southern France. Pediatric Infectious Diseases Journal 17:701-4,1998.

5. Muigai R, Gatei D, Shaunak S, Wozniak A, Bryceson AD. Jejunal function and pathology in visceral leishmaniasis. Lancet 2:476479,1983.

6. Read J, Bethel J, Harris R, Meyer WA, Korelitz J, Mofenson L, Moye J, Phawa S, Rich K, Nugent RP. Serum vitamin A concentrations in a North American cohort of human immunodeficiency virus type 1 infected children. Pediatric Infectious Diseases Journal 18:134-142,1999.

7. Ross AC. Stephensen CB.Vitamia $A$ and retinoids in antiviral responses. FASEB Journal.10: 979-985,1996.

8. Santos LMP, Assis AM, Martins MC, Araújo MPN, Morris SS, Barreto ML. Situação nutricional e alimentar de pré-escolares no semi-árido da Bahia(Brasil): Hipovitaminose A. Revista de Saúde Pública 30:67-74,1996.

9. Schrimshaw NS, Taylor CE, Gordon JE. Interactions of nutrition and infection. American Journal of the Medical Sciences 237:367403,1959.

10. Shankar AH,Genton B, Semba RD. - Effect of vitamin A supplementation on morbidity due to plasmodium falciparum in young children in Papua Guinea: a randomised trial. Lancet 354:201-207,1999.

11. Vieira JBF, Coelho GE. Leishmaniose visceral ou calazar. Aspectos epidemiológicos e de controle. Revista da Sociedade Brasileira de Medicina Tropical 31(supl II):85-92,1998.

12. World Health Organization - Expert Committ. Control of the Leishmaniases. Geneva, 1995. 